\title{
Graphic Poetry: How To Help Students Get The Most Out Of Pictures
}

\author{
River Ya-ling Chiang, Chinese Culture University, Taiwan
}

\begin{abstract}
This paper attempts to give an account of some innovative work in paintings and modern poetry and to show how modern poets, such as Jane Flanders and Anne Sexton, the two American poets in particular, express and develop radically new conventions for their respective arts. Also elaborated are how such changes in artistic techniques are related to profound shifts in intellectual assumptions and how teachers might be able to help their students get the most out of pictures in Graphic Poetry class, apart from simply giving the students the definitions of the so-called "graphic poetry".

Modern visual artists advocate the essential principle that art must set aside the conventions of the recent past and find new forms of expressions. The multiplicity of perspectives, abstraction, and obscurity all characterize the artistic tendencies in the period. Jane Flanders's "Van Gogh's Bed" and Anne Sexton's "The Starry Night" will be taken as examples to explain how the major artists in the period experiment with new forms and advocate theories of art that still exert influences on our ideas about the value of art. In addition, the paper also attempts to focus on the development of the central ideas of the Modernist period from within the mental world of the artists/poets discussed here because, in the poet's/painter's work, there are clear marks of individual character and temperament. Students can be motivated by these marks in the painting and then can easily understand the meaning that a poem conveys and thus enjoy the words and images in it.
\end{abstract}

Keywords: Graphic Poetry; Modern Poetry; Visual Poetics; Visual Learners

\section{INTRODUCTION}

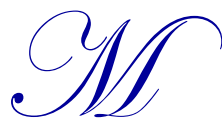

ost students in Poetry class might take it as something really abstract and incomprehensible because of the imagery, symbols, metaphors, and metrics it implies. Most students try to look for connections among the descriptions of images, moods, and attitudes so that they might be able to grasp the meaning and significance in poetry. In short, students take too much time to make sense of it - to interpret it. When they seek to use their rational understanding and intellectual comprehension to interpret poetry, the emotional response and appreciation about the poem itself are usually ignored. However, most students are actually visual learners rather than readers. If professors can use pictures to raise students' interest and thus motivate them to respond to poetry, their students won't think it is inaccessible and difficult. Based on the teaching approach, professors should define graphic poetry as "poetry meant to be seen". The verbal text can be interpreted from a visual dimension. A poem, therefore, is not only a poem, but also a picture.

Theory and practice are inseparable in the poetry of the twentieth century, marked so deeply as it is by social, political, scientific, and cultural changes. Because of the shift with the instability that characterizes the entire period, both theory and practice must be seen as interdependent if one ever hopes to capture the significance of these transformations. The turbulence of cultural events, the fusion of art and life through the subconscious, the search for order in chaos, and the depositing of the poetic function in the visual image all seem to reveal the poets' capacity in the period to rapidly record and historicize events in a manner that is simultaneously dizzying and frightening. The goal of this study is to furnish a theoretical framework for reflections on the pathways taken by modern poetry in the era of specialization. At the same time, it suggests that these increasingly intricate formulations might map out their own zone by allowing the artistic method herein elaborated to be applied to the form of modern poetry. The reader of modern poetry is frequently confused by a body of material that seems to be ambiguous and complex. There lies, in the first place, the possibility that in the apparent chaos of avant-garde Modernist poetry, there is a support that structures and shows an incorporation of visuality in the poem - a depositing of the poetic function in the visual 
image. This kind of visual or experimental poetry experiments with new procedures of composition, aesthetically valid insofar as they reflect a broader ideological order. Therefore, visual or experimental poetry proposes a transformation of the cultural complex out of which it grows.

Clearly, the mere declaration of transgressive principles will not produce poetry which pretends to be "avant-garde." The "procedure", which causes confrontation, is understood here as the means, and then the procedure is also combined in the body of the poem in order to process the poetic function of the work by signs. Such a procedure might come into confrontation with other procedures while other procedures are revealing the dominant ideological complex, and then a new poetic form is thus reflected. In other words, modern poetry of this generation shows its particular characteristics that come after something with different characteristics. This sense of contrast with what has gone before is essential to the characterization of any artistic period. The new poetic form also represents, or even corresponds, with the profound changes in dominant states of mind and feelings of people because these conditions for revolutionary change involve, in particular, a general atmosphere of skepticism which helps examine the languages of the arts. People don't have the confidence or hope about the real world they are in. Rather, they feel anxiety and tend to be more skeptical, even about particular ideas such as the avant-garde. The modern intellectuals, thus, tend to be divorced from, or marginal to, the society in which they live. The common interest of poets and painters also reinforces a sense of marginality. It then develops into profound forms of psychological alienation. This well explains the characteristics of both poetry and art in the Modernist period and furthermore explains why paintings help students to comprehend the meanings of poetry in the period.

\section{DISCUSSION}

Generally, the so-called "graphic poetry" refers to poetry like George Herbert's "Easter Wings." The typography of the poem makes it look exactly like wings. The shape of the poem is like two birds. The original image was shown on two pages of a book, sideways, as shown in Figure 1. The lines suggest two birds flying upward with wings spread out. The poem itself is graphic enough. It looks like an image - a picture. "Graphic poetry" like this could be easier for students to comprehend, but rather than the definition of the so-called "graphic poetry", professors should be more concerned about the methodology they apply in teaching their students. That is, the correlation between poetry and paintings should be the focus. Students have to be the viewers of paintings and also the readers of poetry. Furthermore, students should be expected to be the spectators of poetry. Usually, students may start with searching for some websites related to art and literature. Web-galleries and web-poetry definitely help a lot in doing research or in teaching. Students are more like visual learners nowadays and they are normally good at using the high-tech devices. While searching online, they have been attracted by the paintings already which, at the same time, at least helps to raise their interest in poetry a little bit.

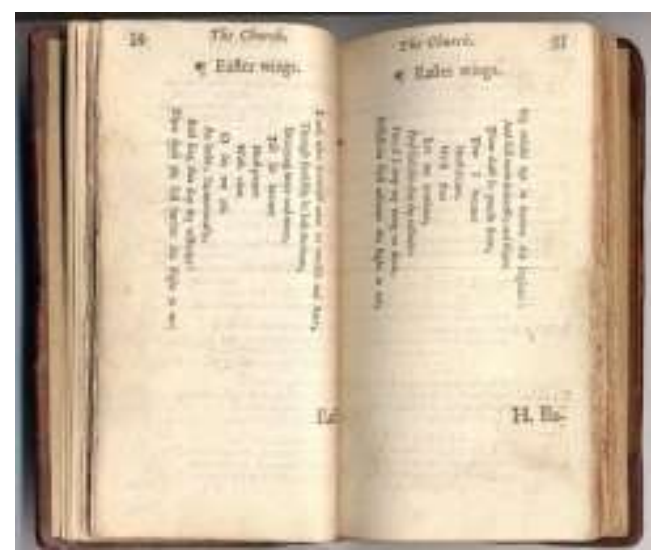

Figure 1: “Easter Wings” by George Herbert (1593-1633)

\footnotetext{
1 "Easter Wings" by George Herbert (1593-1633) is taken as a typical pattern poem in which the reader can find the meaning in the visual structure of the stanzas. The poem is believed to split onto two separate pages, so it must be read sideways. The imagery of the "winged" look seeks to carry the truth and meaning already.
} 
Modernist innovators rely on the idea that creativity and art must be subjective, intuitive, and expressionist in character. As the modern experimental poets lose confidence and give up their attempt to articulate a casually coherent world, their language turns to be more and more elliptical, to juxtaposition, and to the simultaneous and the collaged. While teaching Poetry class, professors can develop their thoughts by outlining modern unrest, free-thinking and the relationship between modern poetry and such characteristics as juxtaposition, simultaneity, and collage in the modern art theories of Cubism, Expressionism, and Surrealism. During class, it is essential for professors to introduce basic concepts related to some art theories because students tend to be more visual learners and their feelings are motivated by seeing pictures. By asking the students to search online resources, especially particular artists' paintings, it might motivate them to find more interest in such a class as they learn more about the similar characteristics between pictures and poetry. For example, the Cubists do not limit themselves to constitute a form of an object only from those planes the eye perceives. By the techniques of discontinuity and juxtaposition, the Cubists make a representation of it. In addition, the idea of simultaneity is expressed in painting by the simultaneous representation of the different figures of a form seen from different points of view. In literature, the idea is similarly expressed by the polyphony of simultaneous voices which say different things. As for the Abstract Expressionists, they attempt to focus on the surface of their paintings, where the qualities of the paint and the canvas reside and their own gestural strokes are recorded. Similarly, modern poets are self-conscious of their poetry. They also emphasize the relationship between the surface of their writings and their own artistic involvement while writing the poems. The surface images seek to reflect a concern for subjectivity and the poems, similar to the abstract paintings, can contain a variety of references simultaneously. The surrealists seek modes of expression to free themselves from the aesthetic, sexual, and psychological preconceptions of their own society. Psychological explanation and the resurgence of myth and dream are taken as alternative sources upon which the surrealists can rely for the meaning of life. Surrealist poets' treatment of the metaphor achieves a combination of emotion, object, and idea, whereas the subliminal combination of the separate, conscious entities of emotion, object, and idea aims to stir the unconscious feeling. They expand Freud's theories in their practice of automatism. Psychoanalysis provides the Surrealists with the alternative source to investigate the introspection of the literary mind.

What really matters is whether students are able to emotionally respond to graphic poetry. Therefore, professors may start from within the mental world of the poets or painters. For example, Jane Flanders, Anne Sexton, and William Carlos Williams are very typical American poets who portray the details of the famous paintings for their readers. Modern visual artists advocate the essential principle that art must set aside the conventions of the recent past and find new forms of expressions. The multiplicity of perspectives, abstraction, and obscurity all characterize the artistic tendencies in the period. Jane Flanders's "Van Gogh's Bed" and Anne Sexton's "The Starry Night" are good examples to explain how the major poets in the period experiment with new forms and advocate theories of art that still exert influences on our ideas about the value of art. In Jane Flanders's "Van Gogh's Bed"2, the poet doesn't put the subject at the beginning of each stanza, but it amazingly leads the reader to read even more carefully about the description of the invisible subject - "Van Gogh's bed". Van Gogh's bed, thus, is viewed via the words of Jane Flanders. It's like students view the painting Vincent's Bedroom in Arles (Figure 2) by Van Gogh and the poem "Van Gogh's Bed" by Jane Flanders as the painting. Such a connection always attracts the students in Poetry class because the poem is apparently visible and visual.

Another example of how a painting can help students comprehend a poem better is Anne Sexton's "The Starry Night". Anne Sexton is known for her autobiographical, confessional verse, while Vincent van Gogh is notable for the bold color and strong emotions in his paintings. Anne Sexton's poetry mostly depicts her suffering from depression and her suicidal tendencies, while Vincent van Gogh's Starry Night (Figure 3) seems to set the tragic painter free from the intensity of passions and mental instability. In Anne Sexton's "The Starry Night", when the poet repeats twice "This is how I want to die", she's not only expressing the suffering, panic, and depression of the painter Vincent van Gogh, but also revealing her own death wish and the desperation deep inside her. In the poet's/painter's work, there are clear marks of individual character and temperament. Students can be motivated by these marks in the painting and can then easily understand the meaning that Anne Sexton's poem conveys, and thus enjoy the words and images in it.

\footnotetext{
2 "Van Gogh's Bed" by Jane Flanders is taken as an ekphrastic poem. The hidden meaning and the state of mind of the painter, Van Gogh, are closely portrayed by the detailed description of the interior of Van Gogh's room through the words of Jane Flanders.
} 


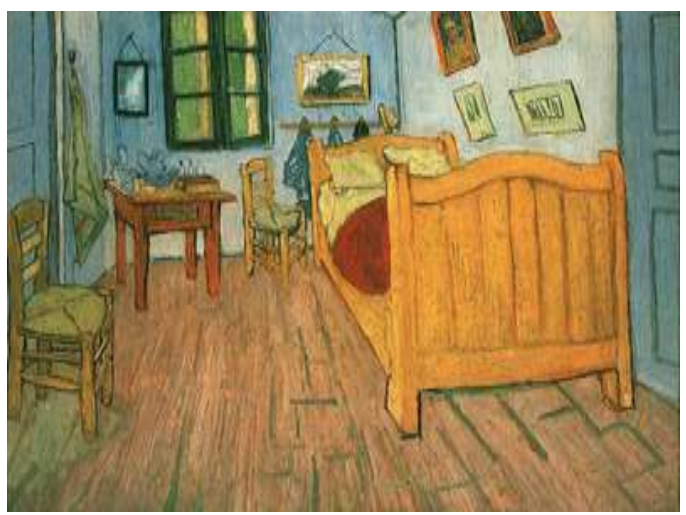

Figure 2: “Vincent's Bedroom In Arles” By Vincent van Gogh (F482, Arles, October 1888)

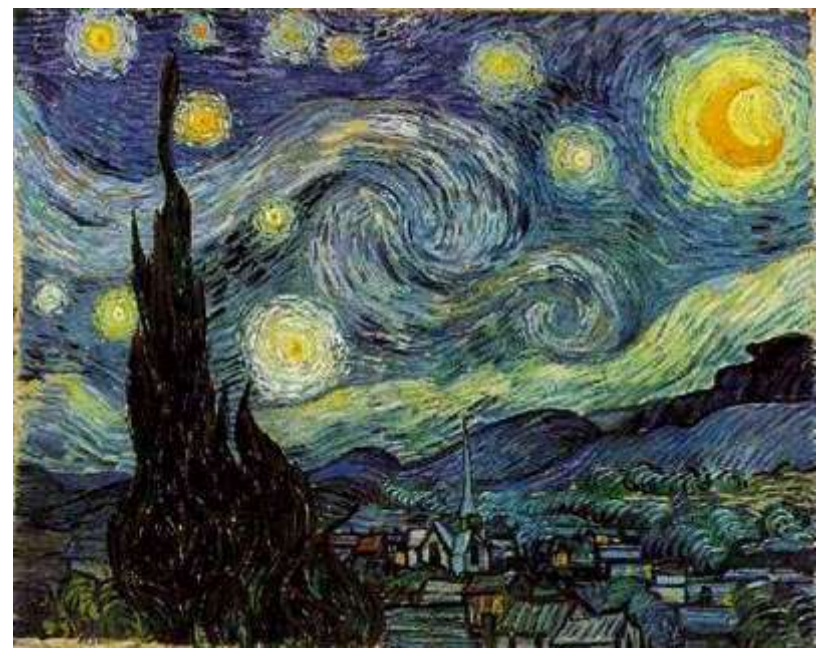

Figure 3: "Starry Night” By Vincent van Gogh (F.612, Saint-Remy, June)

\section{CONCLUSION}

"Graphic poetry" specifically delimits one subdivision of a vast amount of modern poetry produced from the turn of the twentieth century to our own time, and the perfect bridge between modern poetry and visual poetics can be built when the poet/painter increases the impact of visual image and carries out an experiment with pictorial forms to create a moment of epiphany in the poem/painting itself. The great revolution of visual poetics is to make the world the poet's/painter's new representation of it. A poet may select and put images into juxtaposition in separate lines to suggest and call up the state he feels. Free verse, with its peculiar flexibility, is suitable for modern poetry which turns to be introspective and deals with expression of momentary phases in the poet's mind. That is, the principles of poetic expression can link Modernist juxtaposition to a focus on the epiphanic moment. In detecting a crisis in verse and trying to reorder the graphic chaos created by the destruction of linearity, visual poetry emerges. Pictures definitely can help visual learners in the classroom to be more skillful in reading poetry.

\section{AUTHOR INFORMATION}

River Ya-ling Chiang, Due to her keen sensibility and perception of color and words, the author, River Ya-ling Chiang, worked out her MA thesis by analyzing T. S. Eliot's The Waste Land according to the visual perspective, and her Ph.D. dissertation, titled The Correlation Between Modernist Poetry and Visual Art, by consistently exploring the possible interactions between verbal and visual representations. She enjoys the challenge created by the combination of the two fields of art - literature and visual arts - and attempts to fill gaps in visioning the possibilities of pictorial representation and, furthermore, applies the approach to her teaching. E-mail: river911@gmail.com 